\title{
A Comparison of the Solvation Properties of 2-Nitrophenyloctyl Ether, Nitrobenzene, and $n$-Octanol as Assessed by Ion Transfer Experiments
}

\author{
Rubin Gulaboski, ${ }^{\dagger}$ Alexandra Galland, ${ }^{\ddagger}$ Géraldine Bouchard, ${ }^{\ddagger}$ Karolina Caban, ${ }^{\S}$ \\ Ansgar Kretschmer, ${ }^{\dagger}$ Pierre-Alain Carrupt, ${ }^{\ddagger}$ Zbigniew Stojek, ${ }^{\S}$ Hubert H. Girault,, and \\ Fritz Scholz*, \\ Institut für Chemie und Biochemie, Universität Greifswald, Soldmannstrasse 23, \\ D-17489 Greifswald, Germany, Institut de Chimie Thérapeutique, Université de Lausanne, \\ CH-1015 Lausanne, Switzerland, Department of Chemistry, University of Warsaw, \\ Pasteura 1, PL-02-093 Warszawa, Poland, and Laboratoire d'Electrochimie Physique et Analytique, \\ École Polytechnique Fédérale de Lausanne, CH-1015 Lausanne, Switzerland
}

Received: December 2, 2003; In Final Form: February 6, 2004

The lipophilicity of the anionic forms of drugs and model compounds was assessed by their transfer across (i) the water-2-nitrophenyloctyl ether (NPOE), (ii) the water-nitrobenzene (NB), and (iii) the water- $n$ octanol interfaces by using the three-phase electrode technique. The lipophilicities, expressed in terms of logarithm of partition coefficients, range for the studied anions from -3.46 to $0.68\left(\log P_{\mathrm{A}^{-}, \mathrm{aq}}^{\ominus \mathrm{NPOE}}\right)$ for $\mathrm{NPOE}$, from -3.81 to $2.62\left(\log P_{\mathrm{A}^{-} \text {,aq }}^{\ominus N \mathrm{r}}\right.$ ) for $\mathrm{NB}$, and from -6.20 to $-3.20\left(\log P_{\mathrm{A}^{-} \text {,aq }}^{\ominus \mathrm{n} \text { oct }}\right)$ for $n$-octanol. Although NPOE shares with nitrobenzene the aromatic part and with $n$-octanol the hydrophobic carbon chain, only very weak correlation was observed between the NPOE-based data with the $n$-octanol-based data, and the same is true for the correlation of the NB-based and $n$-octanol-based data. However, there is a strong and even linear correlation between the NPOE-based and the NB-based data.

\section{Introduction}

The processes of ion transfer across the interface of two adjacent immiscible liquids attract significant attention due to their wide applicability in different fields such as ion-selective electrodes, phase-transfer catalysis, biomimetic studies of membrane function, drug uptake, and so forth. ${ }^{1-3}$ The standard Gibbs energy of transfer $\left(\Delta G_{i, \alpha}^{\ominus \beta}\right)$ is the major parameter that determines to what extent the ions will be distributed between two adjacent phases. Its value provides information about the solvation strength between the dissolved ions and the surrounding solvent molecules. $\Delta G_{i, \alpha}^{\ominus \beta}$ is directly related to the standard potential of ion transfer $\left(\Delta \phi_{i, \alpha}^{\ominus \beta}\right)$ and standard partition coefficient $\left(P_{i}\right)$ (see eqs 6 and 7 , respectively).

The logarithm of the partition coefficient, $\log P$, measures the lipophilicity of compounds and is one of the major parameters included in quantitative structure properties (QSPR) and quantitative structure activity (QSAR) relationships, playing a crucial role in drug design. ${ }^{1,2}$ Moreover, $\log P$ has been used for predicting various biological properties such as toxicity, ${ }^{2}$ transfer through biological membranes, and affinity between receptors and enzymes. ${ }^{3}$

The classical techniques for the determination of $\log P$ such as the shake-flask method or potentiometric titrations are techniques without external control of the interfacial potential, providing access only to the apparent values of the partition coefficient of ions, ${ }^{4}$ which strongly depend on the experimental

* Corresponding author. Tel: 00493834864 450. Fax: 00493834864 451. E-mail: fscholz@mail.uni-greifswald.de

$\dagger$ Universität Greifswald.

$\doteqdot$ Université de Lausanne.

$\S$ University of Warsaw.

"École Polytechnique Fédérale de Lausanne. conditions, such as the phase-volume ratios and the presence, concentration, and complexation constants of all the ions dissolved in the biphasic system. ${ }^{5,6}$ The introduction of fourelectrode voltammetry at the interface of two immiscible electrolyte solutions (ITIES) led to significant progress in the lipophilicity determinations of different organic and inorganic ions, ${ }^{7-13}$ providing access to the standard values of partition coefficients of ions, which are independent of experimental conditions. The theoretical studies applied to ITIES ${ }^{14-17}$ have significantly contributed to the understanding of the processes occurring at ITIES. Moreover, various experimental modifications ${ }^{18-21}$ have enabled to extend the available potential windows so that the measurement of the lipophilicities even of some heavy metal ions ${ }^{22-24}$ could be performed. The major restrictions of the four-electrode ITIES techniques are due to their applicability to few organic solvents, mainly 1,2-dichlorethane (DCE) ${ }^{13}$ and nitrobenzene (NB), ${ }^{13}$ or lately to 2-nitrophenyloctyl ether (NPOE). ${ }^{22,24-27}$ The nonpolarizability of some important organic solvent-water interfaces such as $n$-octanol-water is one of the weaknesses of this technique.

The recent introduction of the so-called three-phase electrode technique ${ }^{28}$ has overcome the limitations regarding the nonpolarizability of some organic solvent-water interfaces such as that of $n$-octanol, ${ }^{29,30}$ menthol, ${ }^{31}$ or nitrophenyl-nonyl ether, ${ }^{32}$ leading to significant progress in the determination of the lipophilicity of a variety of inorganic and organic ions. ${ }^{33-37}$ Whereas Compton and his group used three-phased electrodes to study the electrochemistry of electroactive liquids, ${ }^{32,38-40}$ Scholz and co-workers ${ }^{28-31,33-37}$ developed the technique of determining the Gibbs energies of ion transfer with the help of solutions of electroactive compounds in droplets of organic solvents immobilized on electrode surfaces. 
The traditionally used measure of lipophilicity as a predictor of solute membrane partitioning is the partition coefficient in the $n$-octanol-water system $\left(\log P_{\text {aq }}^{\text {n-oct }}\right.$, since the long lipophilic chain of $n$-octanol coupled with its hydrophilic hydroxyl group, make it an ideal mimic for the major constituents of the biological membranes (i.e., phospholipides). However, in many other situations, $\log P_{\mathrm{aq}}^{\mathrm{n}-\mathrm{oct}}$ cannot give a good estimate of a drug's absorption or permeation and other solvent systems are needed to yield information which is complementary to $\log$ $P_{\mathrm{aq}}^{\mathrm{n}-\mathrm{oct}}$ data. Particularly the use of the aprotic solvent 1,2dichloroethane (DCE) has experimental benefits in structurepharmacokinetic relationships. ${ }^{1}$ However, the high volatility and the toxicity of DCE limit its value and call for its replacement by a more appropriate organic solvent. Given its promising physicochemical properties and absence of known toxicity, $o$-nitrophenyl octyl ether (NPOE) has recently been introduced in electrochemistry ${ }^{22,24-27}$ and in medicinal chemistry. ${ }^{41,42}$ The intermolecular forces expressed in NPOE-water partitioning were proven similar to the forces encoded in $\log P_{\mathrm{aq}}^{\mathrm{DCE}}$, suggesting $\log P_{\mathrm{aq}}^{\mathrm{NPOE}}$ to offer a convenient alternative to $\log$ $P_{\mathrm{aq}}^{\mathrm{DCE}} \cdot 42$

In this paper the lipophilicity of 27 anionic drugs and model compounds (see Figure 1) were studied in the NPOE-water system and its closely related nitrobenzene (NB)-water system using the three-phase electrode technique. The standard partition coefficient values in these two structurally similar systems were compared with results previously obtained in the $n$-octanolwater systems. ${ }^{30}$

\section{Experimental Section}

2.1. Compounds. All the studied compounds were purchased from Fluka (Buch, Switzerland), except sulfinpyrazone (kindly donated by Novartis Pharma, Basel, Switzerland). NPOE and $n$-octanol were purchased form Acros Organics (Geel, Belgium). All chemicals were of analytical grade and supplied by Fluka.

2.2. Electrochemical Method. A $0.05 \mathrm{~mol} \mathrm{~L}^{-1}$ or $0.1 \mathrm{~mol}$ $\mathrm{L}^{-1}$ solution of decamethylferrocene (noted dmfc) was prepared by dissolving the compound in water-saturated NPOE, NB, or $n$-octanol. A droplet of this solution $(1 \mu \mathrm{L})$ was attached to the surface of a paraffin-impregnated graphite electrode that was subsequently immersed in a NPOE, NB, or $n$-octanol-saturated aqueous solution containing 0.001 to $1.0 \mathrm{~mol} \mathrm{~L}^{-1}$ drug dissolved in $1 \mathrm{~mol} \mathrm{~L}^{-1} \mathrm{NaOH}\left(0.5 \mathrm{~mol} \mathrm{~L}^{-1}\right.$ buffer made of sodium hydrogen phthalate and $\mathrm{HCl}$ was used in the case of maleic acid). $\mathrm{An} \mathrm{Ag} / \mathrm{AgCl}$ (saturated $\mathrm{NaCl}$ solution) reference electrode was used, while a platinum wire served as an auxiliary electrode. All experiments were performed at room temperature. Nitrogen was purged through the solutions for $4 \mathrm{~min}$ prior to each measurement and a nitrogen blanket was maintained thereafter.

Square-wave (SW) voltammograms were recorded using the electrochemical measuring system AUTOLAB PGSTAT 30 (Eco-Chemie, Utrecht, Netherlands). Typical instrumental parameters used for the square-wave voltammetry were the following: SW frequency $f=10 \mathrm{~Hz}, \mathrm{SW}$ amplitude $E_{\mathrm{sw}}=50$ $\mathrm{mV}$, scan increment $\mathrm{d} E=1 \mathrm{mV}$, and starting potential $E_{\mathrm{s}}=$ $-0.5 \mathrm{~V}$.

\section{Principles of the Three-Phase Electrode Approach}

The determination of the lipophilicity of ions by using the three-phase electrode approach is based on the concept of preserving the electroneutrality of both phases. The term "threephase electrode" denotes an electrochemical system where three different phases, in our case a solid electrode (electron conduc-
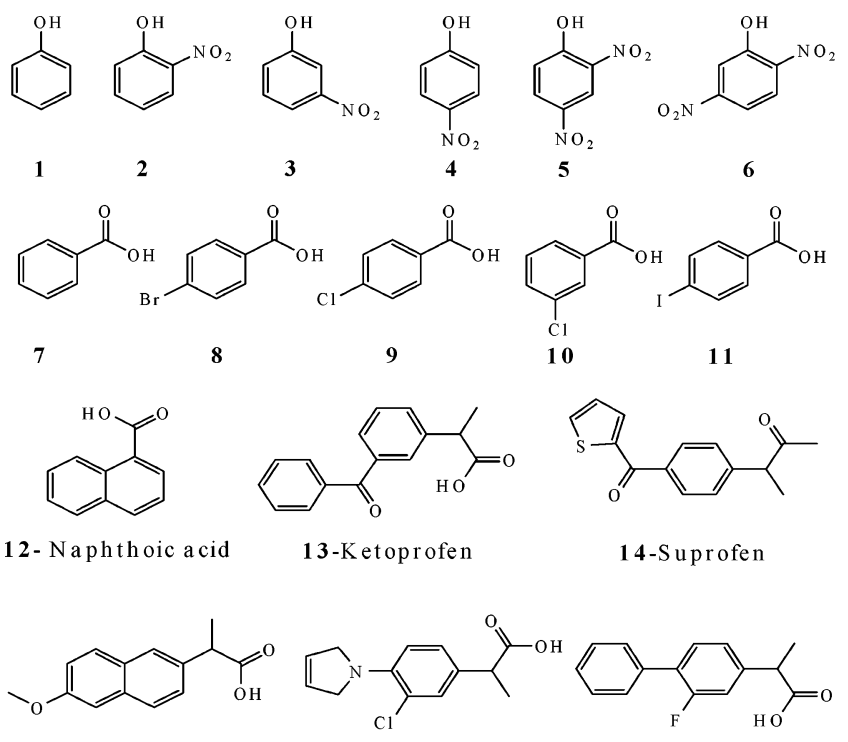

$15-$ Naproxen 16-Pirprofen

17 -F lurbiprofen
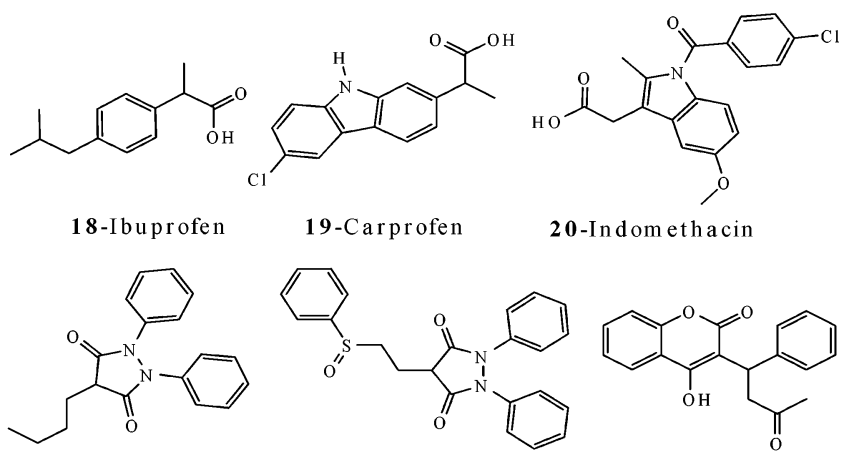

21 -Phenylbutazone

22 -Sulfin pyrazone

23-W arfarin
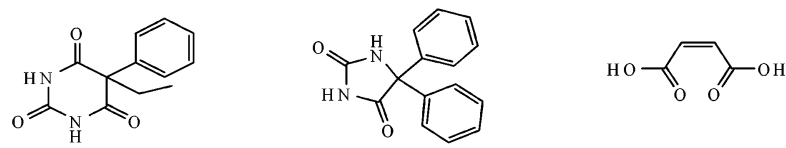

24-Phenobarbital

25-Phenytoin

26-Maleic acid

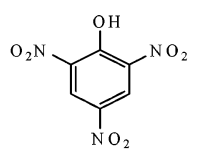

27 -Picric acid

Figure 1. Chemical structures of the compounds that have been studied in their anionic form. 1: Phenol; 2: 2-Nitrophenol; 3: 3-Nitrophenol; 4: 4-Nitrophenol; 5: 2,4-Dinitrophenol; 6: 2,5-Dinitrophenol; 7: Benzoic acid; 8: 4-Bromobenzoic acid; 9: 4-Chlorobenzoic acid; 10: 3-Chlorobenzoic acid; 11: 4-Iodobenzoic acid. The names of the other compounds are given in the figure.

tor), an organic liquid, and an aqueous phase are brought into intimate contact. According to this approach, a neutral electroactive and lipophilic compound is dissolved in the waterimmiscible organic solvent without any additional supporting electrolyte. A droplet of that solution is attached to the surface of the working electrode. This latter, with the attached droplet, is then immersed into the aqueous electrolyte solution. By applying a difference of potential between the working and the reference electrodes in the common three-electrode arrangement, the electrochemical processes occurring at such modified electrodes can be studied (see Figure 2).

Due to the absence of supporting electrolyte in the organic phase, at the beginning of the experiment, the applied potential 


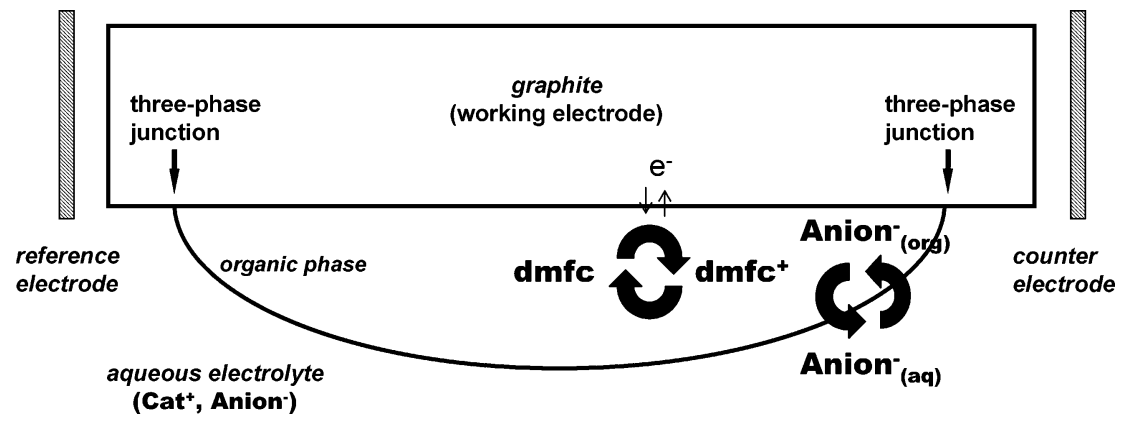

Figure 2. Schematic representation of the processes occurring at the three-phase electrode.

can only act at that three-phase boundary line, inducing the electrochemical reaction of dmfc in the organic phase, simultaneously coupled with the anion transfer across the organic solvent-water interface. The overall process occurring at the three-phase electrode can be described by the following reaction scheme:

$$
\operatorname{dmfc}_{(\mathrm{o})}+\mathrm{A}_{(\mathrm{aq})}^{-}-1 \mathrm{e}^{-} \leftrightarrows \mathrm{dmfc}_{(\mathrm{o})}^{+}+\mathrm{A}_{(\mathrm{o})}^{-}
$$

At equilibrium, the potential difference $E$ between the working electrode and the reference $\mathrm{Ag} / \mathrm{AgCl}$ electrodes is defined as follows:

$E=E_{\mathrm{dmfc}^{+}{ }_{(\mathrm{o})} / \mathrm{dmfc}_{(\mathrm{o})}}^{\ominus}+\Delta \varphi_{\mathrm{A}^{-}, \mathrm{aq}}^{\ominus}+\frac{R T}{n F} \ln \left(\frac{c_{\mathrm{dmfc}^{+}{ }_{(\mathrm{o})}}}{c_{\mathrm{dmfc}_{(\mathrm{o})}}}\right)+\frac{R T}{F} \ln \left(\frac{c_{\mathrm{A}^{-}{ }_{(\mathrm{o})}}}{c_{\mathrm{A}^{-}{ }_{(\mathrm{aq})}}}\right)$

In a first approximation, the activities in the Nernst equation have been replaced by concentrations. In eq $1, E_{\mathrm{dmfc}^{+}{ }_{(0)} \mid \mathrm{dmfc}_{(0)}}^{\ominus}$ is the standard redox potential of the couple $\mathrm{dmfc}^{+} / \mathrm{dmfc}$ in the organic phase (vs $\mathrm{Ag} / \mathrm{AgCl}), n$ is the number of the exchanged electrones ( $n=1$ in this case), $F$ is the Faraday constant (96485 $\left.\mathrm{C} \mathrm{mol}^{-1}\right), R$ is the gas constant $\left(8.314 \mathrm{~J} \mathrm{~mol}^{-1} \mathrm{~K}^{-1}\right)$, and $T$ the temperature in Kelvin; $c_{\mathrm{dmfc}^{+}{ }_{(\mathrm{o})}}$ and $c_{\mathrm{dmfc}_{(\mathrm{o})}}$ are, respectively, the concentrations of $\mathrm{dmfc}^{+}$and dmfc in the organic phase. $\Delta \varphi_{\mathrm{A}^{-}, \text {aq }}^{\ominus}$ is the standard transfer potential of the anions $\mathrm{A}^{-}$from the aqueous to the organic phase, while $c_{\mathrm{A}^{-}{ }_{(\text {(o) }}}$ and $c_{\mathrm{A}^{-}}{ }_{\text {(aq) }}$ are the concentrations of the studied anion in, respectively, the organic and aqueous phases.

The electroneutrality in the organic phase induces eq 2 .

$$
c_{\mathrm{dmfc}^{+}{ }_{(\mathrm{o})}}=c_{\mathrm{A}^{-}{ }_{(\mathrm{o})}}
$$

Moreover, the mass conservation law in the organic phase leads to

$$
c_{\mathrm{dmfc}_{(\mathrm{o})}^{+}}+c_{\mathrm{dmfc}_{(\mathrm{o})}}=c_{\mathrm{dmfc}_{(\mathrm{o})}}^{*}
$$

where $c_{\mathrm{dmfc}_{(\mathrm{o})}}^{*}$ is the initial concentration of dmfc in the organic phase.

When the applied potential is equal to the standard redox potential of the couple $\mathrm{dmfc}^{+} / \mathrm{dmfc}$ in organic phase, then

$$
c_{\mathrm{dmfc}^{+}(\mathrm{o})}=c_{\mathrm{dmfc}_{(\mathrm{o})}}
$$

Then, combining eqs $1-4$, the formal redox potential $\left(E_{\mathrm{f}}\right)$ of the couple $\mathrm{dmfc}^{+} / \mathrm{dmfc}$ in the organic phase is obtained:

$E_{\mathrm{f}}=E_{\mathrm{dmfc}^{+}{ }_{(\mathrm{o})} / \mathrm{dmfc}_{(\mathrm{o})}}^{\ominus}+\Delta \varphi_{\mathrm{A}^{-}, \mathrm{aq}}^{\ominus}-\frac{R T}{F} \ln \left(c_{\mathrm{A}^{-}(\mathrm{aq})}\right)+\frac{R T}{F} \ln \left(\frac{c_{\mathrm{dmfc}_{(\mathrm{o})}}^{*}}{2}\right)$
Equation 5 shows that in these experimental conditions the formal redox potential of $\mathrm{dmfc}$ in the organic phase $\left(E_{\mathrm{f}}\right)$ depends on the nature and the concentration of the transferable anions in aqueous phase.

The three-phase junction line is a prerequisite for performing these experiments. Since no electrolyte is deliberately added to the organic phase, the applied potential can start the electrochemical reaction only at the three-phase junction where all three phases are in intimate contact. The reason for this is that a natural partition will introduce a small amount of salt from the aqueous phase into the very edge region of the droplet. This way the ohmic resistance will decrease to such an extent that the applied potential will drive the electron transfer across the graphite-organic liquid interface and the ion transfer across the organic liquid-aqueous phase interface. The ohmic drop will be negligible at that point. The reaction starts at the threephase line, and extends further toward the center of the droplet $^{43-45}$ due to the electrochemical generation of ions.

The standard transfer potential $\left(\Delta \varphi_{\mathrm{A}^{-}, \mathrm{o} q \mathrm{o}}^{\ominus}\right)$, the standard Gibbs energy of transfer $\left(\Delta G_{\mathrm{A}^{-}, \mathrm{aq}}^{\ominus}\right)$ and the standard partition coefficient $\left(\log P_{\mathrm{A}^{-} \text {,aq }}^{\ominus}\right.$ ) of the studied anions are deduced from the formal potential using eqs 5,6 , and 7 .

$$
\begin{gathered}
\Delta G_{\mathrm{A}^{-}, \mathrm{aq}}^{\ominus}=-z F \Delta \varphi_{\mathrm{A}^{-}, \mathrm{aq}}^{\ominus \circ} \\
\log P_{\mathrm{A}^{-}, \mathrm{aq}}^{\ominus \circ}=-\frac{\Delta G_{\mathrm{A}^{-}, \mathrm{aq}}^{\ominus}}{2.3 R T}
\end{gathered}
$$

where $z$ is the charge number having a negative sign for anions. Eventually, it should be emphasized that the three-phase technique with immobilized droplets of organic solvents is attractive because even very expensive solvents can be studied as some microliters are sufficient.

\section{Results and Discussion}

With the three-phase electrode approach, a pre-requirement in the determination of the standard partition coefficient of anions by using eq 5 is the estimation of the standard redox potential of dmfc in the organic solvent used for the droplet

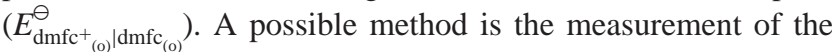
standard redox potential of $\mathrm{dmfc}$ in an electrolytic solution of the studied organic solvent using the common three-electrode configuration (i.e., common measurements in nonaqueous solution in the presence of an internal standard). An alternative method was previously used for the evaluation of the redox potentials of dmfc in $\mathrm{NB}^{34}$ and $n$-octanol, ${ }^{29}$ consisting in applying the three-phase electrode approach to measure the formal potential of dmfc in the presence of various transferring anions with standard transfer potentials known from literature. The obtained $y$-intercept of the linear relationship between $E_{\mathrm{f}}$ and $\Delta \varphi_{\mathrm{A}^{-}, \text {aq }}^{\ominus}$ is related to $E_{\left.\mathrm{dmfc}^{+}{ }_{(0)}\right)}^{\ominus} \mathrm{dmfc}_{(\text {o) }}$ according to eq 5 . The 


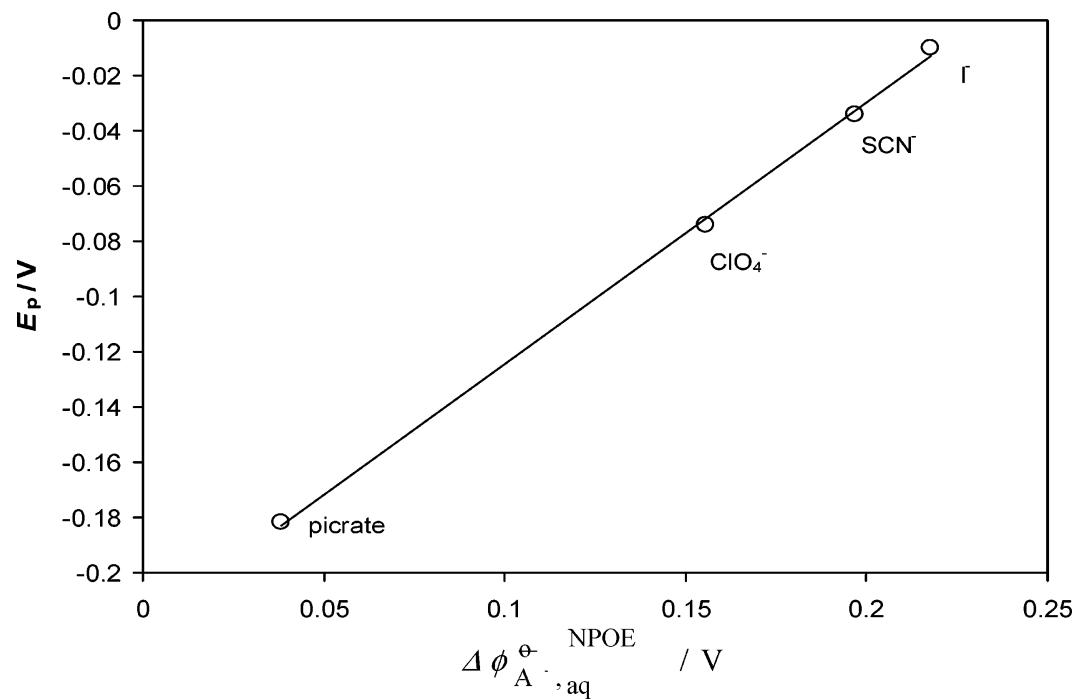

Figure 3. Relationship between the formal potential (i.e., the peak potential in square wave voltammetry) of dmfc in NPOE and the standard transfer potentials of picrate, perchlorate, thiocyanate, and iodine anions across the water-NPOE interface.

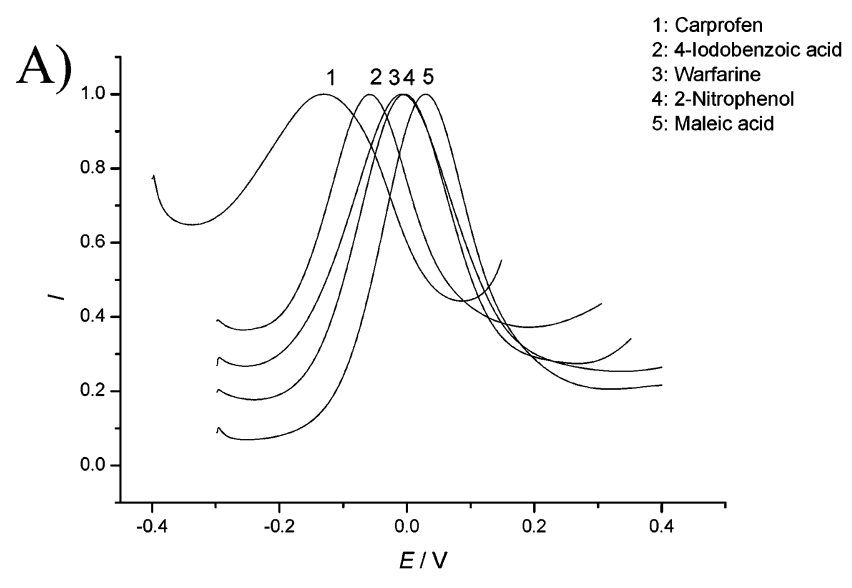

B)

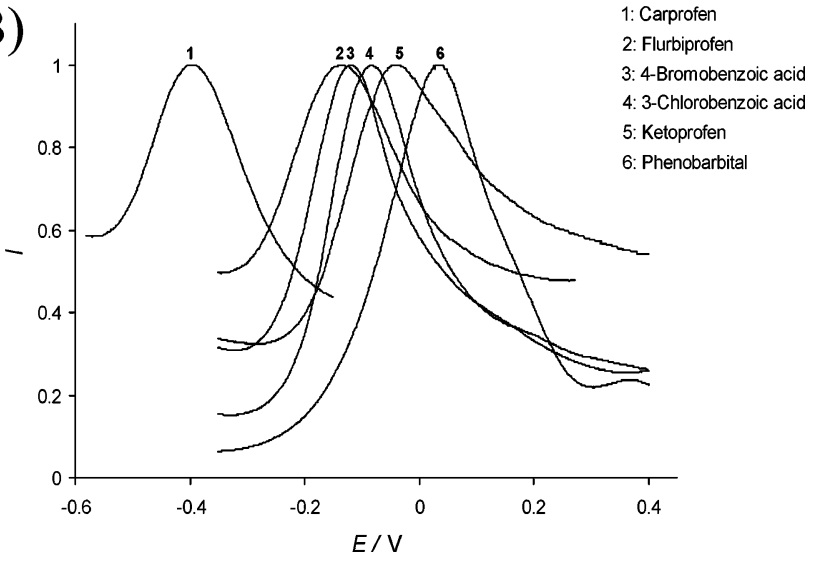

Figure 4. SW voltammograms of dmfc recorded by three phase electrode approach coupled to the transfer of the anions of some of the studied compounds across the water-NPOE interface (A) and waterNB interface (B). The currents in Figure 4 are normalized.

transfer processes of picrate, perchlorate, thiocyanate, and iodide were studied at the water-NPOE interface (see Figure 3), yielding a value of $-0.140 \mathrm{mV}$ (vs $\mathrm{Ag} / \mathrm{AgCl}$ ) for $E_{\mathrm{dmfc}^{+}\left({ }_{0}\right)}^{\ominus} \mid \operatorname{dmfc}_{(\mathrm{o})}$.

The oxidation of dmfc (dissolved either in NPOE or in NB) studied with the help of a three-phase electrode leads to welldefined square-wave voltammograms (see Figure $4 \mathrm{~A}$ and $4 \mathrm{~B}$, respectively). The values of the peak potentials of dmfc depend on the nature and the concentrations of the anions present in the aqueous phase, as predicted by eq 5 . In all cases, the slopes of the linear relationship between $E_{\mathrm{f}}$ and $\log c_{\mathrm{A}^{-}}{ }_{\text {(aq) }}$ are close to the value of $-60 \mathrm{mV}$ as expected by eq 5 . This feature, taken together with the stability of the consecutive cyclic voltammograms, served as a strong argument to assume reversibility of the entire system. The physicochemical data obtained in the $\mathrm{NPOE}$ - water and NB-water systems are compared with the previously determined values in the $n$-octanol-water system in Table 1.

The lipophilicity range of the studied anions was wider for NPOE $\left(-3.46<\log P_{\mathrm{A}^{-} \text {,aq }}^{\ominus \mathrm{NPOE}}<0.68\right)$ and NB $(-3.81<\log$ $\left.P_{\mathrm{A}^{-}, \mathrm{aq}}^{\ominus \mathrm{NB}}<2.62\right)$ than for $n$-octanol $\left(-6.20<\log P_{\mathrm{A}^{-} \text {,aq }}^{\ominus \mathrm{N}-\text { oct }}<\right.$ $-3.20)$, indicating that the differences of solvation energy of anions between water and NPOE (respectively NB) were larger than the difference between $n$-octanol and water. The solubilities of water at $298 \mathrm{~K}$ in NPOE, NB, and $n$-octanol are given in Table 2 . The high water content of $n$-octanol suggests that water molecules dissolved in $n$-octanol strongly participate in the solute solvation, inducing a smaller differentiation of the standard Gibbs energies of transfer of anions across the water$n$-octanol interface.

Figure 5 shows the relationships between the standard partition coefficients of the studied anions in the NPOE-water and NB-water (respectively $n$-octanol-water) systems. We also included the lipophilicity values taken from literature for 5 small monoanions: $\mathrm{ClO}_{4}{ }^{-}\left(\log P_{\mathrm{A}^{-}, \mathrm{aq}}^{\ominus \mathrm{NPOE}}=-3.10, \log P_{\mathrm{A}^{-}, \mathrm{aq}}^{\ominus \mathrm{NB}}=\right.$ -1.36), $\mathrm{SCN}^{-}\left(\log P_{\mathrm{A}^{-}, \mathrm{aq}}^{\ominus \mathrm{NP}}=-4.60, \log P_{\mathrm{A}^{-}, \mathrm{aq}}^{\ominus \mathrm{NB}}=-2.93, \log \right.$ $\left.P_{\mathrm{A}^{-}, \mathrm{aq}}^{\ominus n-\mathrm{oct}}=-5.00\right), \mathrm{I}^{-}\left(\log P_{\mathrm{A}^{-}, \mathrm{aq}}^{\ominus \mathrm{NPOE}}=-4.91, \log P_{\mathrm{A}^{-}, \mathrm{aq}}^{\ominus \mathrm{NB}}=\right.$ $\left.-3.46, \log P_{\mathrm{A}^{-}, \mathrm{aq}}^{\ominus n-\mathrm{ct}}=-5.20\right), \mathrm{NO}_{3}^{-}\left(\log P_{\mathrm{A}^{-}, \mathrm{aq}}^{\ominus \mathrm{NPOE}}=-6.58, \log \right.$ $\left.P_{\mathrm{A}^{-}, \mathrm{aq}}^{\ominus \mathrm{NB}}=-4.47, \log P_{\mathrm{A}^{-}, \mathrm{aq}}^{\ominus n-\mathrm{oct}}=-5.90\right)$, and $\mathrm{Cl}^{-}\left(\log P_{\mathrm{A}^{-}, \mathrm{aq}}^{\ominus \mathrm{NPOE}}=\right.$ $\left.-9.22, \log P_{\mathrm{A}^{-} \text {,aq }}^{\ominus \mathrm{NB}}=-8.03, \log P_{\mathrm{A}^{-} \text {,aq }}^{\ominus n-\text { ct }}=-5.80\right) .^{20-22,29} \mathrm{~A}$ good correlation was obtained between $\log P_{\mathrm{A}^{-}, \mathrm{aq}}^{\ominus \mathrm{NPOE}}$ and $\log$ $P_{\mathrm{A}^{-} \text {,aq }}^{\ominus \mathrm{NB}}$ (eq 8), with a slope close to unity and a $y$-intercept of -0.47 . These results are in agreement with those recently presented by Wilke et al. ${ }^{22}$

$$
\begin{gathered}
\log P_{\mathrm{A}^{-}, \mathrm{aq}}^{\ominus \mathrm{NB}}=0.99( \pm 0.07) \log P_{\mathrm{A}^{-}, \mathrm{aq}}^{\ominus \mathrm{NPOE}}-0.47( \pm 0.27) \\
n=32 ; r^{2}=0.85 ; s=0.73 ; F=160
\end{gathered}
$$

In these and the following equations, 95\% confidence limits are given in parentheses; $n$ is the number of compounds, $r^{2}$ the 
TABLE 1: Standard Gibbs Energies of Transfer and Partition Coefficients of the Studied Anions

\begin{tabular}{|c|c|c|c|c|c|c|c|c|}
\hline & anion of & $\begin{array}{c}\Delta G_{\mathrm{A}^{-}, \mathrm{aq}}^{\ominus \mathrm{NB}} \\
\mathrm{kJ}^{-1} \mathrm{~mol}^{-1}\end{array}$ & $\begin{array}{c}\Delta G_{\mathrm{A}^{-}, \mathrm{aq}}^{\ominus \mathrm{aq}} / \\
\mathrm{kJ} \mathrm{mol}^{-1}\end{array}$ & $\begin{array}{l}\Delta G_{\mathrm{A}^{-}-\mathrm{aq}}^{\ominus \mathrm{oct}} / \\
\mathrm{kJ} \mathrm{mol}^{-1 a}\end{array}$ & $\log P_{\mathrm{A}^{-}, \mathrm{aq}}^{\ominus \mathrm{NB}}$ & $\log P_{\mathrm{A}^{-}, \mathrm{aq}}^{\ominus \mathrm{NPOE}}$ & $\log P_{\mathrm{A}^{-}, \mathrm{aq}}^{\ominus \mathrm{N}-\mathrm{oct}_{a}}$ & $r / \AA^{b}$ \\
\hline 1 & phenol & 20.45 & 19.50 & 23.13 & -3.62 & -3.46 & -4.10 & 2.78 \\
\hline 2 & 2-nitrophenol & 14.60 & 18.00 & 22.56 & -2.59 & -3.19 & -4.00 & 2.98 \\
\hline 3 & 3-nitrophenol & 20.00 & 18.75 & 23.70 & -3.54 & -3.32 & -4.20 & 2.98 \\
\hline 4 & 4-nitrophenol & 21.48 & 17.20 & 24.82 & -3.81 & -3.05 & -4.40 & 2.98 \\
\hline 5 & 2,4-dinitrophenol & 8.70 & 11.62 & 24.25 & -1.54 & -2.06 & -4.30 & 3.15 \\
\hline 6 & 2,5-dinitrophenol & 14.00 & 14.85 & 25.40 & -2.48 & -2.63 & -4.50 & 3.15 \\
\hline 7 & benzoic acid & 21.00 & 18.95 & 32.72 & -3.72 & -3.36 & -5.80 & 2.97 \\
\hline 8 & 4-bromobenzoic acid & 12.00 & 17.32 & 28.20 & -2.13 & -3.07 & -5.00 & 3.15 \\
\hline 9 & 4-chlorobenzoic acid & 12.25 & 15.23 & 31.59 & -2.17 & -2.70 & -5.60 & 3.09 \\
\hline 10 & 3-chlorobenzoic acid & 15.25 & 16.65 & 27.08 & -2.70 & -2.95 & -4.80 & 3.09 \\
\hline 11 & 4-iodobenzoic acid & 14.00 & 12.00 & 28.77 & -2.48 & -2.13 & -5.10 & 3.21 \\
\hline 12 & naphthoic acid & 15.50 & 17.80 & 31.05 & -2.74 & -3.15 & -5.50 & 3.77 \\
\hline 13 & ketoprofen & 19.33 & 18.05 & 28.20 & -3.42 & -3.20 & -5.00 & 3.84 \\
\hline 14 & suprofen & 15.80 & 16.47 & 32.15 & -2.80 & -2.92 & -5.70 & 3.79 \\
\hline 15 & naproxen & 11.50 & 12.86 & 28.77 & -2.04 & -2.28 & -5.10 & 3.70 \\
\hline 16 & pirprofen & 5.65 & 9.55 & 28.75 & -1.00 & -1.69 & -5.10 & 3.76 \\
\hline 17 & flurbiprofen & 10.50 & 12.35 & 24.80 & -1.86 & -2.19 & -4.40 & 3.75 \\
\hline 18 & ibuprofen & 17.40 & 15.34 & 28.77 & -3.08 & -2.72 & -5.10 & 3.59 \\
\hline 19 & carprofen & -14.80 & -3.85 & 18.05 & 2.62 & 0.68 & -3.20 & 3.82 \\
\hline 20 & indomethacin & 11.00 & 15.05 & 26.50 & -1.95 & -2.67 & -4.70 & 4.06 \\
\hline 21 & phenylbutazone & 3.70 & 12.85 & 24.25 & -0.65 & -2.28 & -4.30 & 4.13 \\
\hline 22 & sulfinpyrazone & 7.10 & 12.85 & 24.25 & -1.26 & -2.28 & -4.30 & 4.40 \\
\hline 23 & warfarine & 9.80 & 12.30 & 23.13 & -1.74 & -2.18 & -4.10 & 4.05 \\
\hline 24 & phenobarbital & 26.75 & 24.10 & 31.02 & -4.74 & -4.27 & -5.50 & 3.64 \\
\hline 25 & phenytoine & 17.70 & 19.65 & 30.45 & -3.14 & -3.48 & -5.40 & 3.78 \\
\hline 26 & maleic acid & 20.30 & 19.50 & 31.02 & -3.60 & -3.46 & -5.50 & 2.75 \\
\hline 27 & picric acid & -3.00 & 3.65 & n.m. ${ }^{c}$ & 0.53 & -0.65 & n.m. ${ }^{c}$ & 3.28 \\
\hline
\end{tabular}

${ }^{a}$ Taken from reference $30 .{ }^{b}$ van der Waals radius of the ion. ${ }^{c}$ Not measured

TABLE 2: Physicochemical Properties of NPOE, NB, DCE, and $n$-Octanol, at $298 \mathrm{~K}^{48}$

\begin{tabular}{lccc}
\hline properties & NPOE & NB & $n$-octanol \\
\hline molar mass $\left[\mathrm{g} \mathrm{mol}^{-1}\right]$ & 251.33 & 123.11 & 130.2 \\
density $\left[\mathrm{g} \mathrm{cm}^{-3}\right]$ & 1.041 & 1.198 & 0.825 \\
molar volume $\left[\mathrm{cm}^{3} \mathrm{~mol}^{-1}\right]$ & 241.4 & 1.7 & 160.8 \\
solubility of the solvent in water $\left[\mathrm{mol} \mathrm{L}^{-1}\right]$ & $2.0 \times 10^{-6}$ & 0.2 & $4.1 \times 10^{-3}$ \\
solubility of water in the solvent $\left[\mathrm{mol} \mathrm{L}^{-1}\right]$ & $4.6 \times 10^{-2}$ & 34.8 & 2.4 \\
relative permittivity & 24.2 & 10.3
\end{tabular}

squared correlation coefficient, $s$ the standard deviation, and $F$ the Fischer test.

In general, the Gibbs energy of solvation comprises three terms: ${ }^{46}$ the first one is the Gibbs energy of making a cavity for accommodating the solute in the solvent, while the second term arises from the interactions between the solvent and solute molecules after the solute is accommodated. The third contribution is the reorganization Gibbs energy of solvent molecules around the solute molecules.

The first theory that described the ion-solvent interactions was given from Born ${ }^{46}$ at the beginning of the 20th century. The Born theory describes the ion as a rigid sphere with radius $r$ (equivalent to the crystallographic radius of the ion) and charge $z_{i}$. The solvent, which is polarized in the vicinity of an ion, is represented by a structureless continuum of uniform dielectric constant $\epsilon_{\mathrm{r}}$, corresponding to its bulk value. Despite its limitations (the Born theory neglects the charge delocalization effects and the dielectric saturation, assuming that the dielectric constant around the ion is equal to that in the bulk, which results in an overestimation of ion-solvent interactions values), the Born equation provides good estimates of ionic solvation energy

$$
\Delta G_{\mathrm{IS}}^{\alpha}=-\frac{z^{2} e^{2} N_{\mathrm{A}}}{8 \pi \epsilon_{0} r}\left(1-\frac{1}{\epsilon_{\mathrm{r}}^{\alpha}}\right)
$$

where $\Delta G_{\text {IS }}^{\alpha}$ is the Gibbs energy of solvation of the ions in the solvent $\alpha, z$ and $r$ are, respectively, the charge and the radius of ions, $N_{\mathrm{A}}$ is the Avogadro constant, $\epsilon_{\mathrm{r}}^{\alpha}$ is the dielectric constant of phase $\alpha$, and $\epsilon_{0}$ is the permittivity of vacuum.

Figure 6 shows the relationship between $\Delta G_{\mathrm{A}^{-} \text {,aq }}^{\ominus \mathrm{NPOE}}$ and the reciprocal van der Waals radii of the anions for the 27 compounds shown in Figure 1. The van der Waals radii were calculated with the standard software MOLSV and the atomic radii given by Gavezzotti. ${ }^{47}$ Calculations were performed on a Silicon Graphics Indy R4400 175 MHz using the Sybyl software (Tripos Associates, St. Louis, MO).This relationship was linear for ions with a van der Waals radius less than $3.3 \AA$ (full circles in Figure 6), suggesting that the Born solvation model is adequate for describing the solvation of small anions (see eq $10)$.

$$
\begin{gathered}
\Delta G_{\mathrm{A}^{-}, \mathrm{aq}}^{\ominus \mathrm{NPOE}}=146.4( \pm 15.62)\left(\frac{1}{r}\right)-31.34( \pm 5.72) \\
n=18 ; r^{2}=0.85 ; s=3.87 ; F=89
\end{gathered}
$$

This observation suggests that for small anions the electrostatic contribution to the solvation energy is predominant, but for bigger anions (see open circles in Figure 6) the other energetic contributions such as the cavity formation and the repulsive/ dispersive terms can no longer be neglected.

Opposite to eq 8 , a poor correlation is observed between $\log$ $P_{\mathrm{A}^{-} \text {,aq }}^{\ominus \mathrm{NPOE}}$ and $\log P_{\mathrm{A}^{-} \text {,aq }}^{\ominus n \text { oct }}$ (see the empty squares in Figure 5). This correlation is slightly improved when phenol, 2-nitrophenol, 3-nitrophenol, and 4-nitrophenol are excluded, confirm- 


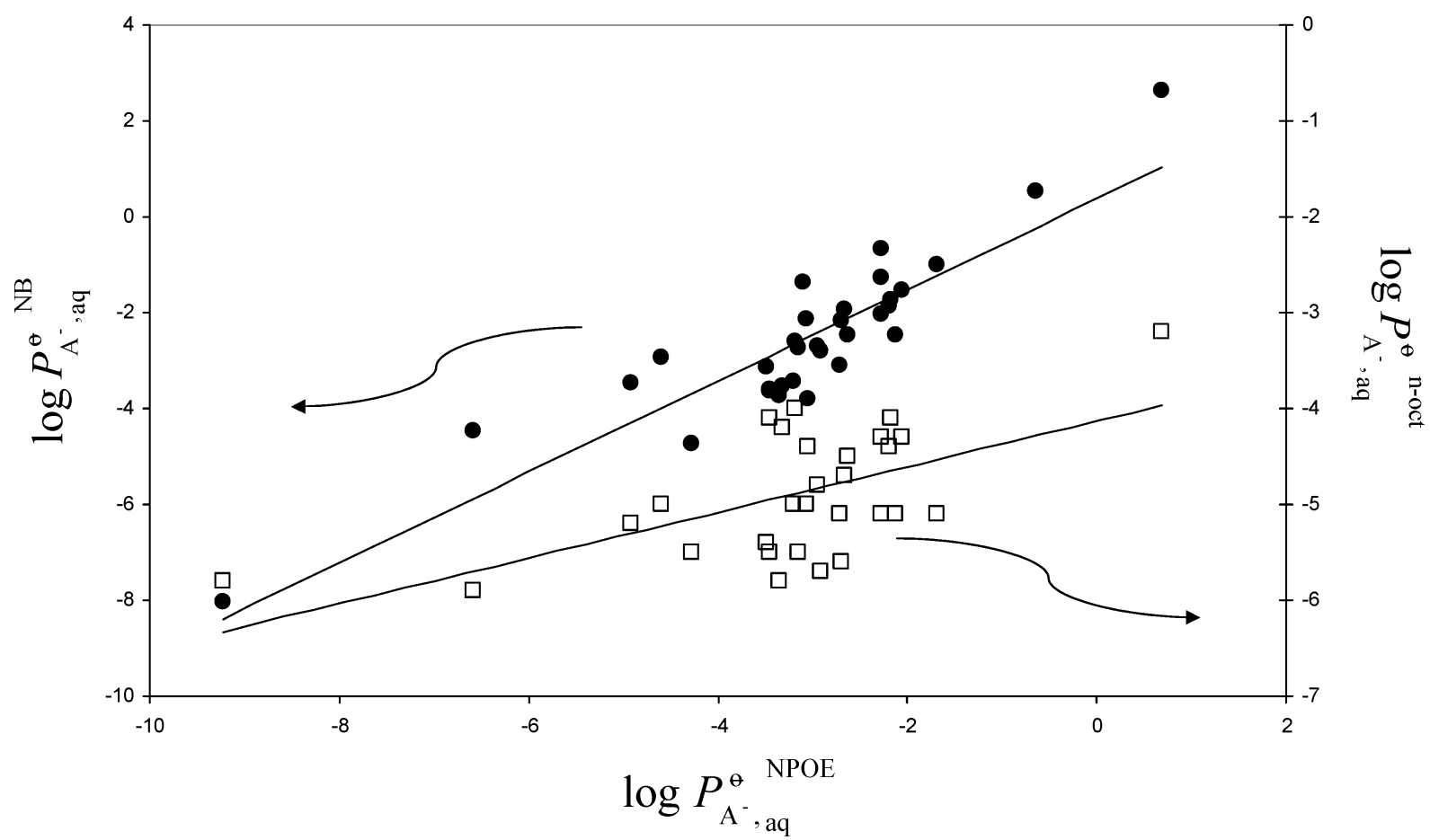

Figure 5. Correlation between $\log P_{\mathrm{A}^{-}, \mathrm{aq}}^{\ominus \mathrm{NPOE}}$ (empty squares) and $\log P_{\mathrm{A}^{-}, \mathrm{aq}}^{\ominus \mathrm{NB}}$ (full circles), respectively, $\log P_{\mathrm{A}^{-}, \mathrm{aq}}^{\ominus n \text { oct }}$, for the 27 anions of the compounds shown in Figures 1 and 5 small anions $\left(\mathrm{ClO}_{4}^{-}, \mathrm{SCN}^{-}, \mathrm{I}^{-}, \mathrm{NO}_{3}^{-2}\right.$, and $\left.\mathrm{Cl}^{-}\right){ }^{20-22,} 29$

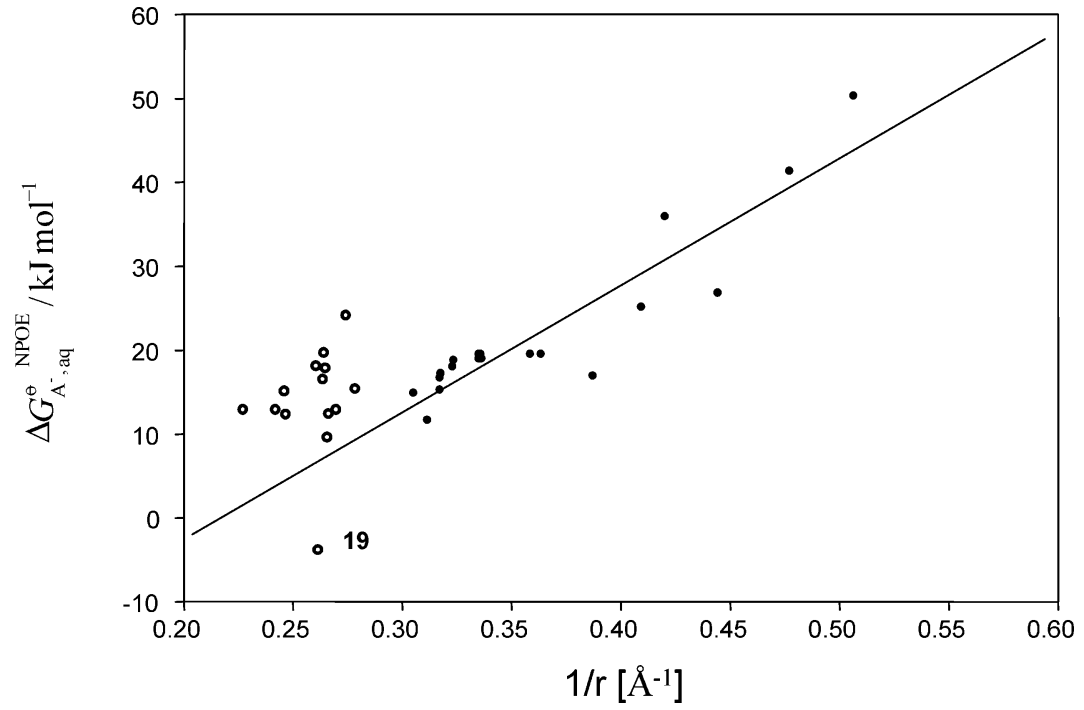

Figure 6. Relationship between $\Delta G_{\mathrm{A}^{-} \text {,aq }}^{\ominus \mathrm{NPOE}}$ and the reciprocal van der Waals radii of the anions of the 27 compounds of Figures 1 and 5 small anions $\left(\mathrm{ClO}_{4}^{-}, \mathrm{SCN}^{-}, \mathrm{I}^{-}, \mathrm{NO}_{3}^{-}\right.$, and $\left.\mathrm{Cl}^{-}\right){ }^{20-22}(\bullet)$ anions with $r$ smaller than $3.3 \AA$; $(\bigcirc)$ anions with $r$ larger than $3.3 \AA$.

ing that the effect of charge delocalization is less important in the $n$-octanol-water system than in the NPOE-water or NBwater systems, as observed previously in 1,2-dichloroethane/ water. ${ }^{4}$ Particularly, the range of the partition coefficients of substituted phenolate and benzoate anions in the $n$-octanolwater system was narrow, suggesting a very small charge delocalization effect on lipophilicity, since for the NPOE-water and $\mathrm{NB}$-water systems these values depended more strongly on charge delocalization. Due to its amphiphilic structure and its high water content, $n$-octanol is a less effective solvent for distinguishing the solutes with respect to charge-dispersion effects.

As noted above, a feature that distinguishes the lipophilicity data obtained in NPOE (and NB) from those in $n$-octanol is the charge delocalization effect. The Gibbs energies of partition of substituted phenolate and benzoate anions for water-n-octanol are very similar, i.e., there is obviously only a very small charge delocalization effect. For the water-NPOE and water-NB systems the values are clearly much more strongly dependent on charge delocalization. This can be seen from Figure 7 where the $\log P_{\mathrm{A}^{-} \text {,aq }}^{\ominus \mathrm{NB}}$ and $\log P_{\mathrm{A}^{-} \text {,aq }}^{\ominus \text { aq }}$ values of the substituted nitrophenolates are plotted versus the $\mathrm{p} K_{\mathrm{a}}$ values of the corresponding compounds. Similar correlations (not shown here) exist for the partition coefficients with $\mathrm{p} K_{\mathrm{a}}$ values of the substituted benzoic acids in NB and of nitrophenolates and substituted benzoic acids in NPOE. $n$-Octanol by itself, and probably the more by its rather high water content, is a much more water-like solvent than NPOE and NB. This makes $n$-octanol a less effective solvent for distinguishing the solutes with respect to charge dispersion.

The cavity formation energy term is proportional to the dimensions of the solute molecules. Figure 8 shows the 


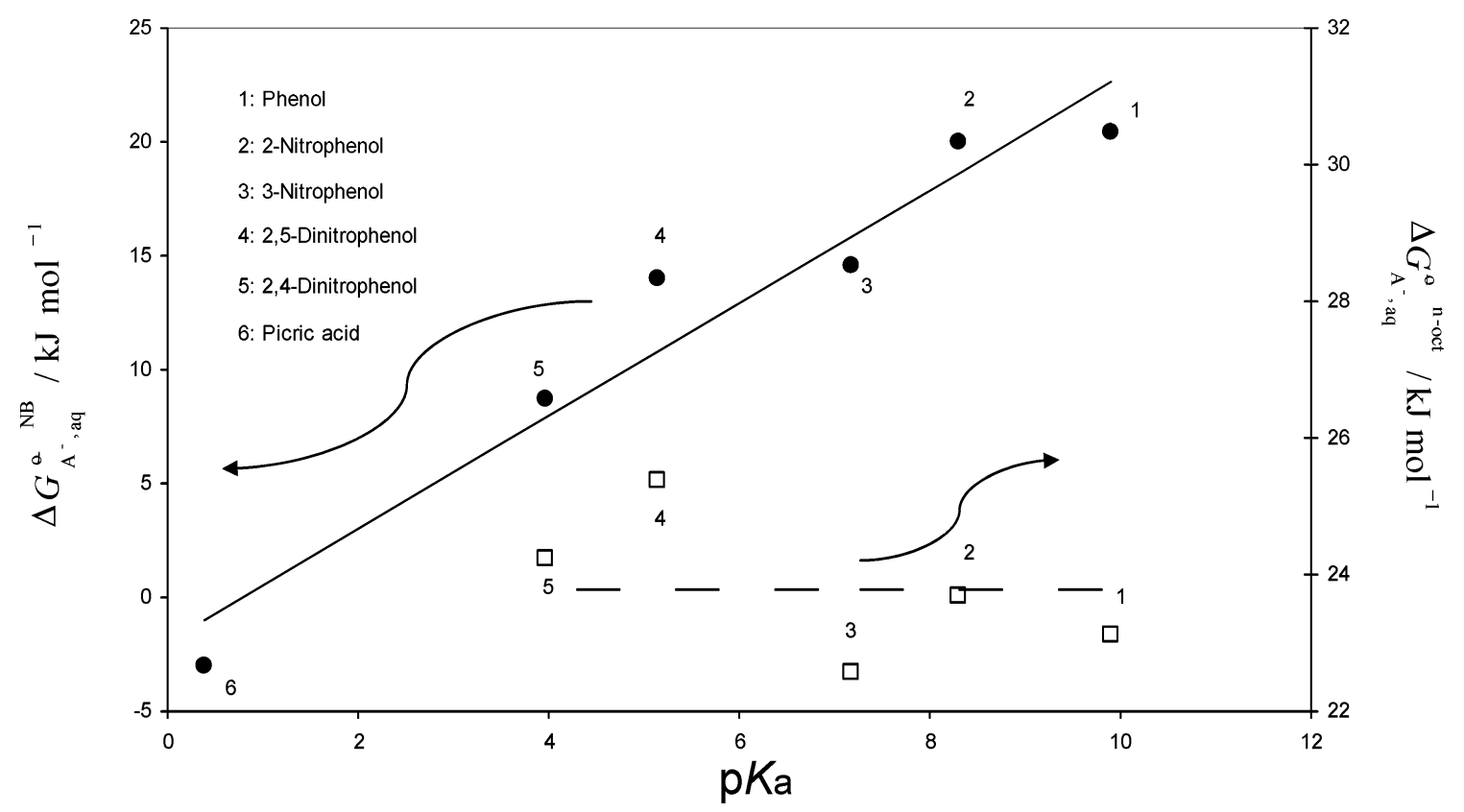

Figure 7. Dependence of the standard Gibbs energies of transfer of monoanionic forms of substituted nitro phenols at the water-NB (full circles) and water- $n$-oct (empty squares) interfaces on their $\mathrm{pKa}$ values in water.

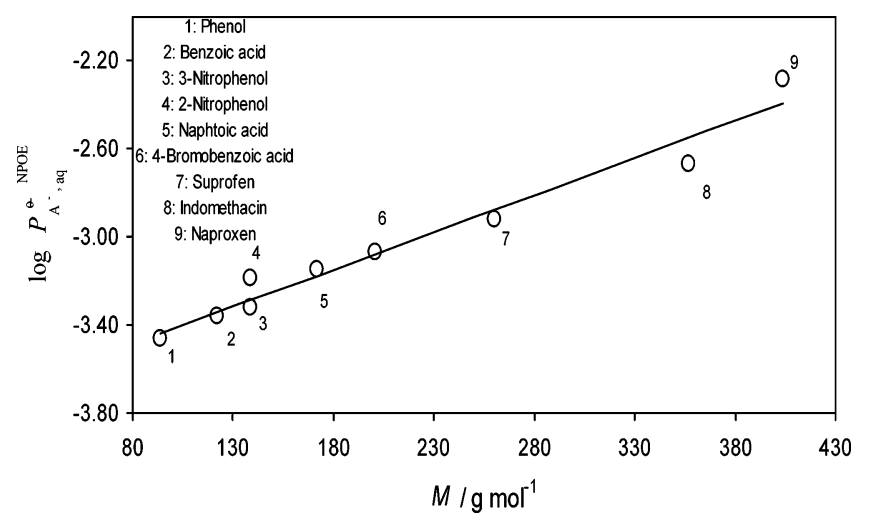

Figure 8. Correlation between $\log P_{\mathrm{A}^{-}, \mathrm{aq}}^{\ominus \mathrm{NPOE}}$ and the molecular weights of some of the transferable compounds.

dependence of the $\log P_{\mathrm{A}^{-} \text {,aq }}^{\ominus \mathrm{NPE}}$ values on the molar mass of some transferable compounds (an identical dependence exists when $\log P_{\mathrm{A}^{-} \text {,aq }}^{\ominus \mathrm{NPOE}}$ is plotted versus the molecular volumes that were estimated using the radii given in Table 1). Obviously, a good correlation exists between $\log P_{\mathrm{A}^{-}, \mathrm{aq}}^{\ominus \mathrm{NPOE}}$ and $M\left(r^{2}=0.97\right)$. The cavity-formation energy for accommodating a particular solute in the given solvent can be calculated knowing the surface tension of this solvent $(\gamma)$ and the surface area of the solute molecules $(A)$, (i.e., $\partial G=4 \times \gamma \times \partial A$ ). Assuming the sphere approximation for the solute molecules and knowing the densities of their solutions, one can relatively precisely estimate the surface area of these molecules, and consequently, the corresponding energy of making a cavity for accommodating them in the solvent. For the compounds of Figure 8, the estimated energetic differences of the cavity formation for the neutral compounds are in rather good agreement with the experimentally determined differences between the standard Gibbs energies of transfer of the corresponding anions. However, the estimated and the experimentally determined differences in cavity formation energies for the compounds with strong charge delocalization effects and those of the bulky molecules do not match. The partition data of these compounds are not correlated with the molar masses and therefore they are not included in Figure 8.
At the end, it should be mentioned that the compounds containing a pyrrole ring in their structures, such as carprofen, pirprofen, or indomethacin, exhibit stronger lipophilic properties in all studied systems than other similar compounds of their groups. The lipophilicity is especially pronounced in the case of a conjugated pyrrole ring, as in carprofen (see Table 1). A similar behavior has been recently observed for the amino acid tryptophan ${ }^{36}$ and peptides containing this amino acid. ${ }^{35}$ In the tryptophan molecule there is also a pyrrole ring conjugated with the aromatic ring, which results in unusual lipophilic properties compared to other amino acids.

\section{Conclusion}

In this paper we have determined the lipophilicity data of a number of anions of drugs and model compounds at the waternitrophenyloctyl ether (NPOE) and water-nitrobenzene (NB) interfaces by using the three-phase electrode approach. Since NPOE shares with nitrobenzene the aromatic part and with $n$-octanol the hydrophobic carbon chain, it was possible to elucidate the interaction site in the NPOE solvent molecules by comparing the lipophilicity of the studied compounds in NPOE with that in NB and $n$-octanol. For both inorganic and organic anions it appears that NPOE is more similar to NB than to $n$-octanol.

It has been also shown how the lipophilicities determined in all solvents depend on ionic radii, charge delocalization effects, and the molecular size of the investigated compounds. An unusually high lipophilicity has been observed for compounds that contain a pyrrole ring. This feature has been observed in our previous studies of the lipophilicity of the amino acid tryptophan and also for peptides that contain tryptophan. Since many biologically important compounds contain a pyrrole ring, this feature deserves attention.

Acknowledgment. F.S. acknowledges support by Deutsche Forschungemeinschaft (DFG) and Fonds der Chemischen Industrie (FCI), R.G. thanks Deutscher Akademischer Austauschdienst (DAAD) for provision of a Ph.D. scholarship, K.C. thanks DAAD for support. P.-A.C. and H.H.G. are indebted to the Swiss National Science Foundation for support. 


\section{References and Notes}

(1) Leo, A.; Hansch, C.; Elkins, D. Chem. Rev. 1971, 71, 525

(2) Testa, B.; van de Waterbeemd, H.; Folkers, G.; Gay, R. Pharmacokinetic Optimization in Drug Research; Wiley-VCH: Weinheim, Germany, 2001; Chapter 6, pp 591-613.

(3) Volkov, A. G. Liquid Interfaces in Chemical, Biological and Pharmaceutical Applications; Marcel Dekker: New York, 2001; Vol. 95 , Chapter 2, pp 487-584

(4) Bouchard, G.; Carrupt, P.-A.; Testa, B.; Gobry, V.; Girault, H. H. Chem. Eur. J. 2002, 8, 3478.

(5) Bouchard, G.; Carrupt, P.-A.; Testa, B.; Gobry, V.; Girault, H. H. Pharm. Res. 2001, 18, 702

(6) Kakiuchi, T. Anal. Chem. 1996, 68, 3658.

(7) Reymond, F.; Fermin, D.; Lee, H. J.; Girault, H. H. Electrochim. Acta 2000, 45, 2647.

(8) Chopineaux-Courtois, V.; Reymond, F.; Bouchard, G.; Carrupt, P.A.; Testa, B.; Girault, H. H. J. Am. Chem. Soc. 1999, 121, 743

(9) Manzanares, J. A.; Allen, R. A. M.; Kontturi, K. J. Electroanal. Chem. 2000, 483, 188. 10884

(11) Ulmeanu, S. M.; Jensen, H.; Samec, Z.; Bouchard, G.; Carrupt, P.-A.; Girault, H. H. J. Electroanal. Chem. 2002, 530, 10.

(12) Chopineaux-Courtois, V.; Reymond, F.; Bouchard, G.; Carrupt, P.A.; Girault, H. H. J. Am. Chem. Soc. 1999, 121, 1743.

(13) Marcus, Y. Ion Properties; Marcel Dekker: New York, 1997; Chapter 15, pp 209-226.

(14) Reymond, F.; Brevet, P. F.; Carrupt, P.-A.; Girault, H. H. J. Electroanal. Chem. 1997, 424, 121.

(15) Reymond, F.; Carrupt, P.-A.; Girault, H. H. J. Electroanal. Chem. 1998, 449, 49

(16) Reymond, F; Lagger, G.; Carrupt, P.-A.; Girault, H. H. J. Electroanal. Chem. 1998, 451, 59.

(17) Volkov, A. G. Liquid Interfaces in Chemical, Biological and Pharmaceutical Applications; Marcel Dekker: New York, 2001; Vol. 95, Chapter 2, pp 373-397.

(18) Beriet, C.; Girault, H. H. J. Electroanal. Chem. 1998, 444, 219

(19) Wilke, S.; Wang, H.; Girault, H. H. J. Electroanal. Chem. 1997, 436,53

(20) Wilke, S.; Zerihun, T. Electrochim. Acta 1998, 44, 15.

(21) Wilke, S.; Wang, H. J. Electroanal. Chem. 1999, 475, 9.

(22) Wilke, S.; Zerihun, T. J. Electroanal. Chem. 2001, 515, 52

(23) Tomaszewski, L.; Lagger, G.; Girault, H. H. Anal. Chem. 1999 71,837

(24) Hundhammer, B.; Solomon, T.; Zerihun, T.; Abegaz, M.; Bekele, A.; Greichen, K. J. Electroanal. Chem. 1999, 371, 1.
(25) Wilke, S. Hablitation Thesis, Halle, 2002.

(26) Samec, Z.; Langmaier, J.; Trojanek, A.; Samcova, E; Malek, J. Anal. Sci. 1998, 14, 35 .

(27) Quinn, B.; Lahtinen, R.; Kontturi, K. J. Electroanal. Chem. 1997. 436, 285.

(28) Scholz, F.; Komorsky-Lovrić, Š.; Lovrić, M. Electrochem. Commun. 2000, $2,112$.

(29) Gulaboski, R.; Mirčeski, V.; Scholz, F. Electrochem. Commun. 2002, 4, 277

(30) Bouchard, G.; Galland, A.; Carrupt, P.-A.; Gulaboski, R.; Mirčeski, V.; Scholz, F.; Girault, H. H. Phys. Chem. Chem. Phys. 2003, 5, 3748.

(31) Scholz, F.; Gulaboski, R.; Mirčeski, V.; Langer, P. Electrochem. Commun. 2002, 4, 659 .

(32) Wain, A. J.; Lawrence, N. S.; Greene, P. R.; Wadhawan, J. D. Compton, R. G. Phys. Chem. Chem. Phys. 2003, 5, 1867.

(33) Gulaboski, R.; Riedl, K.; Scholz, F. Phys. Chem. Chem. Phys. 2003, 5,1284 .

(34) Komorsky-Lovrić, Š.; Riedl, K.; Gulaboski, R.; Mirčeski, V.; Scholz, F. Langmuir 2002, 18, 8000. Komorsky-Lovrić, S.; Riedl, K.; Gulaboski, R.; Mirčeski, V.; Scholz, F. Langmuir 2003, 19, 3090.

(35) Gulaboski, R.; Scholz, F. J. Phys. Chem. B 2003, 107, 5650

(36) Gulaboski, R.; Mirčeski, V.; Scholz, F. Amino Acids 2003, 24, 149.

(37) Mirčeski, V.; Gulaboski, R.; Scholz, F. Electrochem. Commun. 2002, 4,813 .

(38) Schröder, U.; Wadhawan, J.; Evans, R. G.; Compton, R. G.; Wood, B.; Walton, D. J.; France, R. R.; Marken, F.; Bulman Page, P. C.; Hayman, C. M. J. Phys. Chem. B 2001, 106, 8697.

(39) Schröder, U.; Compton, R. G.; Marken, F.; Bull, S. D.; Davies, S. G.; Gilmour, S. J. Phys. Chem. B 2001, 105, 1344.

(40) Wain, A. J.; Wadhawan, J. D.; Compton, R. G. Chem. Phys. Chem 2003, 4, 974

(41) Liu, X.; Bouchard, G.; Müller, N.; Galland, A.; Girault, H.; Testa, B.; Carrupt, P.-A. Helv. Chim. Acta 2003, 86, 3533.

(42) Liu, X.; Bouchard, G.; Girault, H. H.; Testa, B.; Carrupt, P.-A. Anal. Chem. 2003, 75, 7036

(43) Donten, M.; Stojek, Z.; Scholz, F. Electrochem. Commun. 2002 4,324 .

(44) Tasakorn, P.; Chen, J.; Aoki, K. J. Electroanal. Chem. 2002, 533 , 119.

(45) Aoki, K.; Tasakorn, P.; Chen, J. Y. J. Electroanal. Chem. 2003, 542,51 .

(46) Born, M. Z. Phys. 1920, 1, 45.

(47) Gavezzotti, A. J. Am. Chem. Soc. 1983, 105, 5220.

(48) Samec, Z.; Langmaier, J.; Trojanek, A. J. Electroanal. Chem. 1996, 409,1 . 